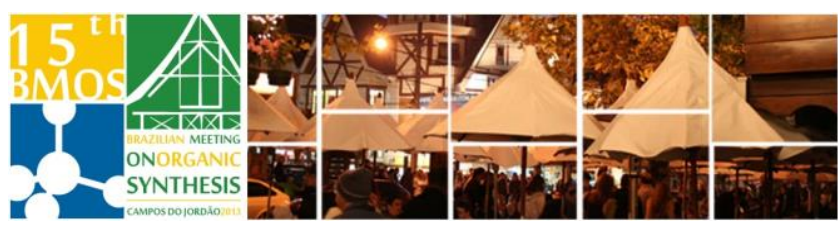

\title{
An expeditious approach to (+)-polyoxamic acid and derivatives from asymmetric Morita-Baylis-Hillman reaction.
}

\section{Bruno Boni Guidotti, José Tiago Menezes Correia, Hamid Ullah, Fernando Antônio Santos Coelho*.}

\author{
Chemistry Institute, State University of Campinas, UNICAMP, C.P. 6154, Campinas, SP, (Brazil)
}

*email: Coelho@iqm.unicamp.br:

Keywords: Morita-Baylis-Hillman,Polyoxamic Acid, Antibacterial.

\section{INTRODUCTION}

Polyoxins are natural nucleoside peptides isolated from strains of Streptomyces cacoi var. asoensis which present a relevant antifungal activity by inhibition of chitin synthase. ${ }^{1}$ The preparation of polyoxins is focused on the synthesis of the a-amino acid portion, (+)-polyoxamic acid, since the synthesis of its nucleoside residue is well described in literature. The purpose of this work is to propose a new approach to the synthesis of (+)-polyoxamic acid and derivatives starting from an asymmetric Morita-Baylis-Hillman (MBH) reaction. The antibacterial profile of these derivatives will be also evaluated.

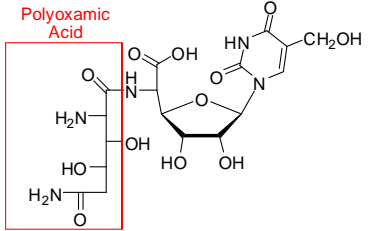

a

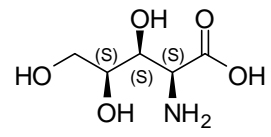

b
Figure 1. a)A polyoxin'; b) (+)-polyoxamic acid.

\section{RESULTS AND DISCUSSION}

The synthesis of 6 began with a $\mathrm{MBH}$ reaction between $(R)-(+)$-glyceraldehyde acetonide 1 and methyl-acrylate, according to a condition previously developed in our laboratory. ${ }^{2}$ This reaction gave a mixture of diastereoisomers (1:5), which was directly treated with $\mathrm{TBSCl} / \mathrm{Imidazole}$ to give the corresponding silyl ethers. After protection, the diastereoisomers are easily separated by column chromatography. The relative and absolute stereochemistries of both diastereoisomers are being confirmed. The major adduct (3) was used for further transformations. So, a solution of $\mathbf{3}$ in $\mathrm{MeOH}$ was treated at $-78 \stackrel{\circ}{\circ}$, with a flush of $\mathrm{O}_{3}$ temperature for $15 \mathrm{~min}$. After that the reaction was treated with $\mathrm{S}(\mathrm{Me})_{2}$ and $\mathrm{NH}_{4} \mathrm{OH} . \mathrm{HCl}$ in the presence of pyridine to give oxime 4 , in $85 \%$ yield (over 2 steps). Although, we have observed a mixture of diastereoisomeric oximes no separation was provided in this step. A solution of the diasteroisomeric oximes in $\mathrm{EtOH}$ was then reduced in the presence of $\mathrm{NaBH}_{3} \mathrm{CN} / \mathrm{MoCl}_{5}$ to afford aminoester $\mathbf{6}$, with excellent anti-diastereoselectivity and $68 \%$ yield.

$$
\text { (1) }
$$

Scheme 1. A new approach to the synthesis of a derivative of polioxamic acid.

In the next steps, the ester and the acetal groups will be hydrolyzed and TBS group will be removed to finish the synthesis of a polyoxamic acid isomer. The stereochemistry of $\alpha$-carbonyl stereocenter will be confirmed by the preparation of the $\mathrm{N}, \mathrm{O}$-acetal 7. By changing the aldehyde used as starting material this approach can allow the synthesis of several derivatives of polyoxamic acid. The antibacterial profile of these derivatives will be screened against some Staphilococcus aureus strains.

\section{CONCLUSION}

A new approach to the synthesis of polyoxamic acid derivatives is being established from an asymmetric Morita-Baylis-Hillman. This approach is fast, straightforward and can provide several substances with great biological potential.

\section{ACKNOWLEDGEMENTS}

We are grateful to CNPq, CAPES and FAPESP for the financial support and to Mr. Edson Gilberto Avansini for technical assistance.

\section{REFERENCES}

Isono, K.; Asahi, A.; Suzuki, S. J. Am. Chem. Soc. 1969, 91, 7490-7505.

Porto, R. S., Amarante, G. W., Cavallaro, M., Poppi, R. J., Coelho, F. Tetrahedron Letters, 2009, 50, 1184-1187. 